\title{
Left-right judgment of haptic stimuli representing the human hand
}

\author{
Maria Luiza Rangel ${ }^{1}$, Sabrina Guimarães-Silva², Andrea Laudares Marques¹, Lucia Riggio ${ }^{3}$, \\ Antonio Pereira ${ }^{4}$, Allan Pablo Lameira ${ }^{5}$, Luiz G. Gawryszewski ${ }^{1}$ \\ 1- Universidade Federal Fluminense, Niterói, RJ, Brazil \\ 2- Universidade Estácio de Sá, Rio de Janeiro, RJ, Brazil \\ 3- Universitá Degli Studi di Parma, PR, Italy \\ 4- Universidade Federal do Rio Grande do Norte, Natal, RN, Brazil \\ 5- Escola Superior da Amazônia, Belém, PA, Brazil
}

\begin{abstract}
The handedness recognition of visually perceived body parts engages motor representations that are constrained by the same biomechanical factors that limit the execution of real movements. In the present study, we used small plastic cutouts that represented the human hand to investigate the properties of mental images generated during their haptic exploration. Our working hypothesis was that any handedness recognition task that involves body parts depends on motor imagery. Forty-four blindfolded, right-handed volunteers participated in a handedness evaluation experiment using their index finger to explore either the back or palm view of a haptic stimulus that represented the human hand. The stimuli were presented in four different orientations, and we measured the subjects' response times. Our results showed that stimulus configurations that resemble awkward positions of the human hand are associated with longer response times $(p<.006)$, indicating that the haptic exploration of stimuli that represent body parts also leads to motor imagery that is constrained by biomechanical factors. Keywords: haptic exploration, motor imagery, handedness recognition, mirror neurons, mental rotation.
\end{abstract}

Received 12 November 2010; received in revised form 12 December 2010; accepted 14 October 2010. Available on line 28 December 2010

\section{Introduction}

Mental rotation was first demonstrated by Shepard and Metzler (1971). Subjects had to decide whether a pair of three-dimensional drawings of objects, in which the right picture was rotated a certain amount from the left picture, were identical or mirror images of each other. The main finding was that manual reaction times rose linearly with increased angular disparity between the two objects, suggesting that objects are rotated in the mind similarly to the physical rotation (Shepard \& Metzler, 1971).

When judging the handedness ${ }^{1}$ of drawings that represent the human hand presented in several orientations, however,

Maria Luiza Rangel, Andrea Laudares Marques, and Luiz G. Gawryszewski, Departamento de Neurobiologia, Universidade Federal Fluminense, Niterói, RJ, Brazil. Sabrina Guimaraes-Silva, Universidade Estácio de Sá, Rio de Janeiro, RJ, Brazil. Lucia Riggio, Universitá Degli Studi di Parma, PR, Italy. Antonio Pereira, Edmond and Lily Safra International Institute of Neuroscience of Natal, Universidade Federal do Rio Grande do Norte, Natal, RN, Brazil. Allan Pablo Lameira, ESAMAZ - CPÓS: Escola Superior da Amazônia, Centro de Pós-graduação, Belém, PA, Brazil. Correspondence regarding this article should be directed to: Maria Luiza Rangel, Universidade Federal Fluminense, Departamento de Neurobiologia - PPG em Neurociências. - Campus Valonguinho, Centro, Niterói - RJ CEP 24210-130. Tel: +55-21-2629-2271. Fax: + 55-21-26292303. E-mail: mlurangel@gmail.com this linear association between angle and reaction time disappears. This is because biomechanical constraints that normally restrict the actual movement of body parts also influence their implicit movement (Parsons, 1987, 1994; Petit, Pegna, Mayer, \& Hauert, 2003). Movements that are difficult to execute, for example, are also difficult to be mentally simulated and lead to longer reaction times (Gawryszewski, Silva-dos-Santos, Santos-Silva, Lameira, \& Pereira, 2007; Lameira, Guimarães Silva, Werneck-Galvão, Pereira, \& Gawryszewski, 2008a; Parsons, 1987, 1994).

The mental rotation of objects perceived haptically has been investigated previously (for review, see Prather \& Sathian, 2002). Numerous tactile stimuli have been used in such studies, including raised dot patterns that represent abstract forms (Dellantonio \& Spagnollo, 1990), alphanumeric stimuli (Rösler, Röder, Heil, \& Hennighausen, 1993), cutout letters (Prather \& Sathian, 2002; Hunt, Janssen, Dagostino, \& Gruber, 1989), and geometric shapes (Marmor \& Zaback, 1976). For inanimate objects, manual reaction time depends only on angular disparity (or the angular deviation from

\footnotetext{
${ }^{1}$ In the handedness recognition paradigm pictures of hands, assuming either common or uncommon postures are presented to the participants and they are required to decide whether the pictures represent the left or right hand.
} 
the canonical orientation; Marmor \& Zaback, 1976; Dellantonio \& Spagnollo, 1990; Hunt et al., 1989).

Few studies have examined the haptic exploration of stimuli that represent body parts (Kilgour \& Lederman 2002, 2006; Kitada, Johnsrude, Kochiyama, \& Lederman, 2009; Kitada, Dijkerman, Soo, \& Lederman, 2010). Additionally, none of these studies investigated specifically motor simulation evoked by the handedness recognition task, but rather the dynamics of the haptic identification of body parts.

Object recognition that relies exclusively on the haptic system is sequential by nature and consequently more feature-based than configuration-based (Lakatos \& Marks, 1999). Vision, in contrast, depends on both feature and configuration processing of object properties (James, James, Humphrey, \& Goodale, 2005). The corollary of these findings is that handedness recognition that depends only on haptic inputs should require more time than multimodal situations (i.e., when visual and haptic information is available) or when only vision is used (Norman, Norman, Clayton, Lianekhammy, \& Zielke, 2004).

The present study used a mental chronometry paradigm to evaluate whether the covert brain processes engaged during a handedness judgment task are independent of stimulus modality. Our experimental subjects were blindfolded and instructed to use haptic exploration to determine the handedness of small cutouts that represented the human hand. Our hypothesis was that response time varies as a function of figure orientation, demonstrating that motor imagery is implicitly evoked during the task.

\section{Methods}

\section{Experiment 1: Palm view}

\section{Participants}

This experiment involved 22 right-handed (Oldfield, 1971) volunteers (13 females and 9 males, 17-24 years old, mean $=19.73$; standard deviation $=0.37$ ), whom were all naive about the purposes of the experiment. A written informed consent was obtained from all volunteers. The study was approved by our institution's Ethics Committee.

\section{Apparatus and procedure}

Small plastic cutouts that represented either the left or right hand $(0.5 \mathrm{~mm}$ height, $4.0 \mathrm{~cm}$ width, $5.5 \mathrm{~cm}$ length) were presented in four distinct orientations to the subjects in a semi-random order in the horizontal plane. In the $0^{\circ}$ orientation, the fingers were positioned away from the subject. The other orientations were $90^{\circ}$ lateral $\left(90^{\circ} \mathrm{L}\right.$, fingers positioned away from the subject's midline), $180^{\circ}$, and $90^{\circ}$ medial $\left(90^{\circ} \mathrm{M}\right.$, fingers positioned toward the midline; see Figure 1).

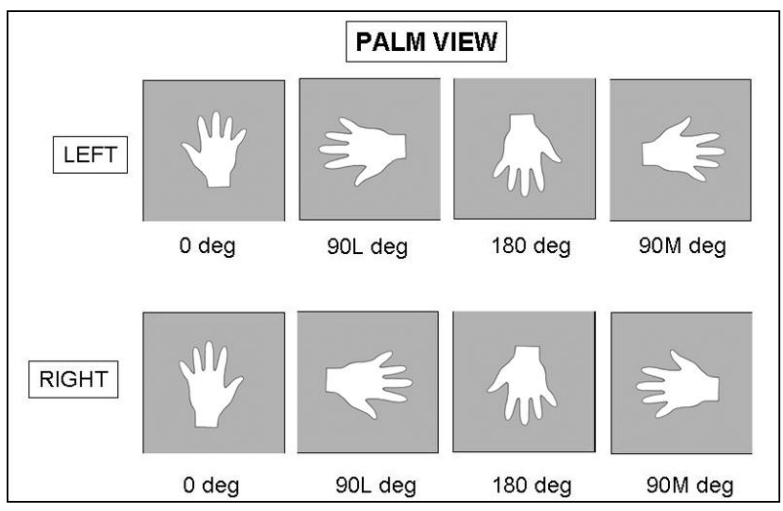

Figure 1. Schematic representation of the stimuli used in the experiments. In Experiment 1, the volunteers explored the object haptically as if it represented the palm view of a human hand and decided on its handedness. In Experiment 2, the volunteers instead considered that the object represented the back of a hand. In this case, the upper-row stimuli represent the right hand, and the lower-row stimuli represent the left hand.

The experiment was divided into two sessions conducted on different days. Each session had 24 training and 40 experimental trials. The first session was considered a practice session and was not included in the statistical analysis. Half of the volunteers (11 subjects) used the left hand in the first session and the right hand in the second session (Right Hand Group), whereas the other half (11 subjects) did the reverse (Left Hand Group).

The volunteers were blindfolded and seated with their arms resting in a prone posture (palms down). They were instructed to consider the stimulus as the palm view of a human hand. Their index finger was gently positioned to contact the thumb representation of the stimulus (start point). After pressing a microswitch located underneath the figure, the volunteer began the haptic exploration. The subjects then announced their decisions about the handedness of the stimulus to the experimenter, who immediately pressed either key 1 (for left) or 2 (for right), on a keyboard. Depending on whether the subject's answer was correct or incorrect, the computer emitted either a high $(2000 \mathrm{~Hz})$ or low $(200 \mathrm{~Hz})$ frequency warning sound, respectively. MEL 2.0 software was used to measure and record response times.

\section{Experiment 2: Back view}

The purpose of Experiment 2 was to investigate the mental properties of the haptic representation of the back view of a hand. Parsons (1994) showed that the mental simulation involved in a visual handedness recognition task for the back view of a hand differs from the palm view. Thus, we expected that a similar pattern would be observed in the haptic handedness test (i.e., an absence of a difference in response times for $90^{\circ} \mathrm{L}$ and $90^{\circ} \mathrm{M}$ when the backs of the hands are 
Table 1. Mean $( \pm S E M)$ percentage of correct responses as a function of angle. No significant difference was observed in performance across the stimulus orientations.

\begin{tabular}{lcccc}
\hline View & $\mathbf{0}^{\mathbf{0}}$ & $\mathbf{9 0}^{\mathbf{0}}$ lateral & $\mathbf{1 8 0}^{\mathbf{0}}$ & $\mathbf{9 0}^{\mathbf{0}}$ medial \\
\hline Palm & $98.2 \pm 1.09$ & $97.7 \pm 1.17$ & $96.8 \pm 1.12$ & $97.3 \pm 1.23$ \\
Back & $99.5 \pm 0.45$ & $99.1 \pm 0.64$ & $96.8 \pm 1.29$ & $97.7 \pm 0.97$ \\
\hline
\end{tabular}

explored haptically). A difference between these two orientations may indicate that the properties of visual and tactile mental imagery are not congruent.

\section{Participants}

This experiment involved 22 volunteers (13 females and 9 males, 18-26 years old, mean $=20.14$; standard deviation $=0.54)$, classified as right-handed (Oldfield, 1971) and naive about the purposes of the experiment. A written informed consent was obtained from all volunteers.

\section{Apparatus and procedure}

The only difference between Experiments 1 and 2 were the instructions given to the volunteers. In Experiment 2, the volunteers were told that the stimuli represented the back of a human hand.

\section{Results}

\section{Performance accuracy}

\section{Experiment 1: Palm view}

A three-way analysis of variance (ANOVA) with one between-subjects factor (Hand Group; haptic task performed with left or right index finger, with two levels) and two within-subjects factors (Stimulus, with two levels; Angle, with four levels) was performed with the number of correct responses as the dependent variable. During the experiment, each condition was performed five times for a total of 40 trials. We found a significant two-way interaction between Stimulus and Angle $(F[3,60]=$ 3.00; $p<.0377)$ and a three-way interaction between Hand Group, Stimulus, and Angle $(F[3,60]=5.11$; $p<.0032$ ). The three-way interaction led us to run separate ANOVAs for each Hand Group, with two within-subjects factors (Stimulus, with two levels; Angle, with four levels). The results for the Left Hand Group (haptic task performed with left hand) showed no significant effect. The analysis of the Right Hand Group (haptic task performed with right hand) showed a significant interaction between Stimulus and Angle $(F[3,60]=4.51 ; p<.0100)$, with the right $90^{\circ} \mathrm{M}$ stimulus producing lower performance accuracy than the left $90^{\circ} \mathrm{M}$ stimulus and than the right $0^{\circ}$ stimulus. Overall, no accuracy differences were found among the stimulus orientations (Table 1).

\section{Experiment 2: Back view}

We performed a three-way ANOVA with one betweensubjects factor (Hand Group, with two levels) and two within-subjects factors (Stimulus, with two levels; Angle, with four levels) with the number of correct responses as the dependent variable. The analysis showed no significant main effect or interaction. See Table 1 for direct comparisons between angles and performance accuracy.

\section{Response time analysis}

The mean values of correct response times for each view (palm or back) were subjected to an ANOVA with one between-subjects factor (Hand Group; haptic task performed with left or right index finger) and two within-subjects factors (Stimulus, left or right hand; Angle, $\left.0^{\circ}, 90^{\circ} \mathrm{L}, 180^{\circ}, 90^{\circ} \mathrm{M}\right)$.

\section{Experiment 1: Palm view}

A significant effect of Angle was observed on response time $(F[3,60]=6.68 ; p<.0006$; see Figure 2$)$. No other factor and no interaction between factors had significant effects on response time. The post hoc comparisons with the Newman-Keuls method showed that the response time for a stimulus oriented at $0^{\circ}(5299 \pm 263 \mathrm{~ms})$ was faster than a stimulus oriented at either $90^{\circ} \mathrm{L}(6025 \pm$ $278 \mathrm{~ms})$ or $180^{\circ}(6073 \pm 289 \mathrm{~ms} ; p<.05)$, but not for a stimulus oriented at $90^{\circ} \mathrm{M}(5387 \pm 255 \mathrm{~ms})$. Additionally, the response time for a stimulus oriented at $90^{\circ} \mathrm{M}(5387 \pm$ $255 \mathrm{~ms})$ was faster $(p<.05)$ than stimuli oriented at $90^{\circ} \mathrm{L}$ $(6025 \pm 278 \mathrm{~ms})$ and $180^{\circ}(6073 \pm 289 \mathrm{~ms})$.

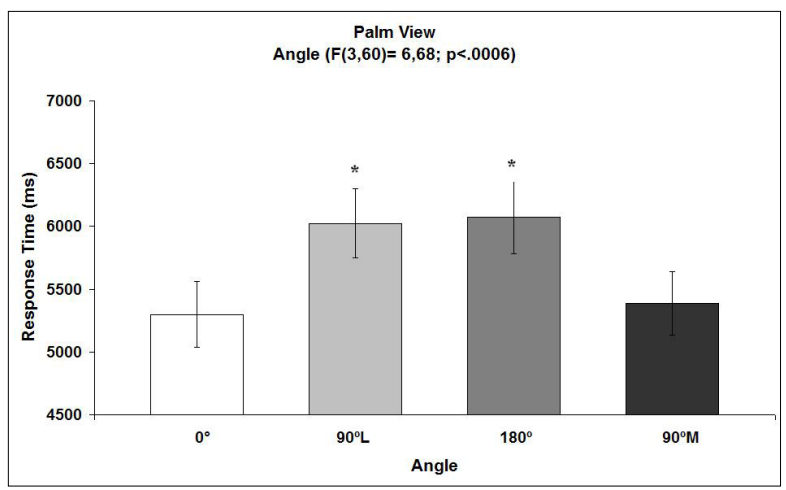

Figure 2. Response time $( \pm S E M)$ as a function of the orientation of the haptic stimulus that represented the palm of a human hand. The response times for the $0^{\circ}$ and $90^{\circ} \mathrm{M}$ orientations did not differ but were shorter than the $90^{\circ} \mathrm{L}$ and $180^{\circ}$ orientations, which did not differ. 
These results show that response time is constrained by the same biomechanical limitations of real movements, suggesting that the mental simulation of implicit hand movements is necessary for the handedness evaluation of a haptic stimulus that represents a body part (i.e., hand). More specifically, response time varies according to the orientation of the object and is slower for both the $90^{\circ} \mathrm{L}$ and $180^{\circ}$ orientations than for the $0^{\circ}$ and $90^{\circ} \mathrm{M}$ orientations. A significant difference was observed between response times for the $90^{\circ} \mathrm{L}$ and $90^{\circ} \mathrm{M}$ orientations. Similar to the visual task (Parsons, 1987, 1994), longer response times are associated with the awkwardness of the implicit movement, indicating that the object is processed as a body part and not as an external object and that implicit movements of the right or the left hand are necessary for handedness discrimination. The main factor Stimulus (right/left) did not reach significance $(p=.88)$, indicating that the response times for recognizing stimuli that represented the left hand did not differ from the response times that represented the right hand.

\section{Experiment 2: Back view}

A significant effect of Angle was observed on response time $(F[3,20]=17.13 ; p<.0001$; see Figure 3 ), with a significant interaction between Group and Stimulus $(F[3,20]=7.44 ; p<.013$; see Figure 4$)$. For the factor Angle, the post hoc comparison using the Newman-Keuls method showed that the response time for the $0^{\circ}$ orientation $(5438 \pm 312 \mathrm{~ms})$ was faster than both the $180^{\circ}(6822 \pm 388 \mathrm{~ms})$ and $90^{\circ} \mathrm{M}(6124 \pm 361$ $\mathrm{ms})$ orientations $(p<.05)$, but not faster than the $90^{\circ} \mathrm{L}$ orientation $(5806 \pm 345 \mathrm{~ms})$. The response time for the $180^{\circ}$ orientation $(6822 \pm 388 \mathrm{~ms})$ was slower than both the $90^{\circ} \mathrm{L}(5806 \pm 345 \mathrm{~ms})$ and $90^{\circ} \mathrm{M}(6124 \pm 361 \mathrm{~ms})$ orientations $(p<.05)$. Finally, no significant difference was found between the response times for $90^{\circ} \mathrm{L}(5806 \pm$ $345 \mathrm{~ms})$ and $90^{\circ} \mathrm{M}(6124 \pm 361 \mathrm{~ms})$ orientations.

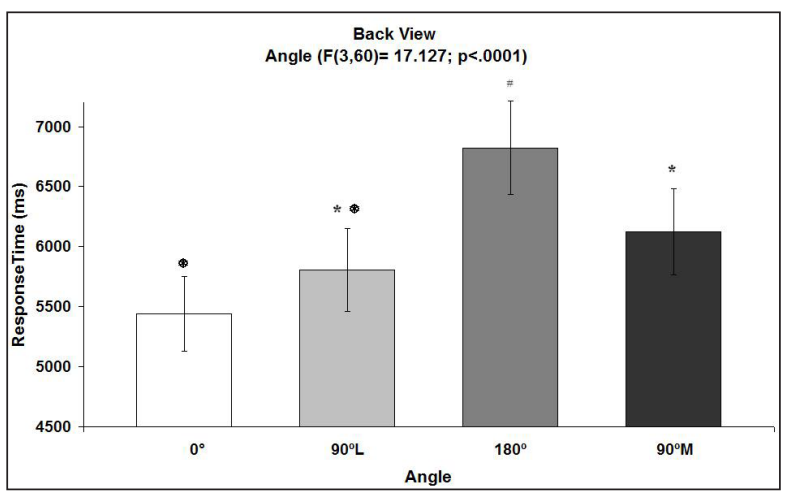

Figure 3. Response time $( \pm S E M)$ as a function of the orientation of the haptic stimulus that represented the back of a human hand. The response times for the $0^{\circ}$ and $90^{\circ} \mathrm{L}$ orientations did not differ but were shorter than the $180^{\circ}$ orientation. No significant difference was observed between the responses times for the $90^{\circ} \mathrm{L}$ and $90^{\circ} \mathrm{M}$ orientations.
Our main finding was that the handedness recognition of haptic stimuli that represent the back of a human hand depends on orientation of the stimuli, similar to what happens with visually perceived body parts. The response times were slower for the $180^{\circ}$ than for the $0^{\circ}, 90^{\circ} \mathrm{L}$, and $90^{\circ} \mathrm{M}$ orientations, and a significant difference was observed between the response times for the $0^{\circ}$ and $90^{\circ} \mathrm{M}$ orientations. However, no significant difference was found between the response times for the $90^{\circ} \mathrm{L}(5806 \pm 345 \mathrm{~ms})$ and $90^{\circ} \mathrm{M}(6124 \pm 361 \mathrm{~ms})$ orientations. The longer response times observed for the $180^{\circ}$ orientation may be attributable to the awkwardness of the associated implicit movement, indicating that the stimulus object is processed as a body part and not as an external object and that implicit movements of the right or the left hand are required for handedness discrimination. The main factor Stimulus (right/left) did not reach significance $(p=.82)$, indicating that the response times for recognizing stimuli that represent the left hand did not differ from the right hand.

The interaction between Hand Group and Stimulus $(F[3,20]=7.44 ; p<.013$; see Figure 4$)$ indicates that when volunteers used the left index finger to explore the test object, the response time was faster when recognizing a right hand stimulus than a left hand stimulus. The inverse occurred with the right index finger. The use of orthogonal planned comparisons showed that when the task was executed with the right hand, the responses were faster for the left hand stimulus $(5747 \pm 353 \mathrm{~ms})$ than the right hand stimulus $(6109 \pm 309 \mathrm{~ms})(p<.05)$. Similar results were observed when the left index was used for exploring the stimuli: there is a trend $(p<$ .092) for faster responses for recognizing a right hand stimulus $(6014 \pm 284 \mathrm{~ms})$ than for recognizing a left hand stimulus $(6321 \pm 342 \mathrm{~ms})$. These results showed unexpected interference between motor commands issued to the exploring hand and the mental simulation involved in handedness judgment. We suggest that this is further evidence of somatomotor involvement in the haptic handedness discrimination task.

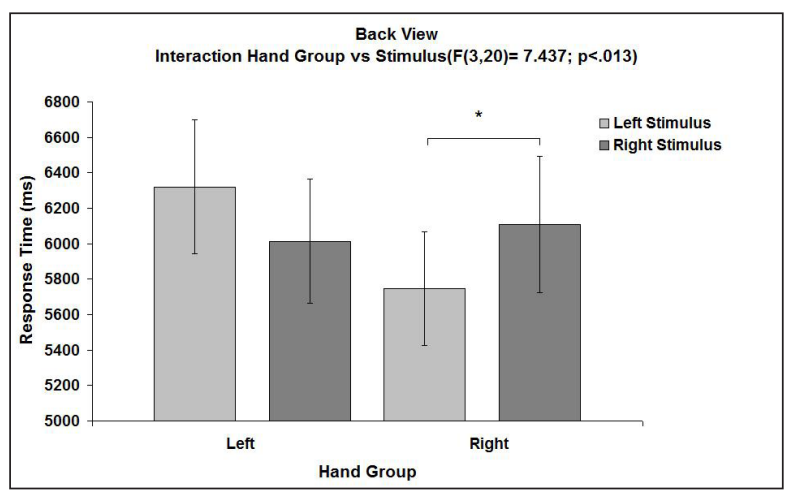

Figure 4. Response time $( \pm S E M)$ as a function of the handedness of the subject's exploring finger (left/right) and the haptic stimulus (left/right hand). 


\section{Discussion}

We used a handedness recognition task to show that the mental simulation of hand movements can be initiated by haptic exploration. The handedness recognition paradigm is known to depend on implicit motor simulation (Jeannerod, 2001) and has been used mostly with visual stimuli (Parsons, 1994; Gawryszewski et al., 2007; Lameira et al., 2008a; Lameira et al., 2008b). The present work is the first to investigate the haptic properties of motor simulation in a handedness recognition task.

The mentally simulated movements used for handedness recognition in visual tasks have been shown to activate cortical areas involved in motor control. For example, a PET study showed that Brodmann areas 44, 46 , and 4 in the left hemisphere and Brodmann areas 6 , 7 , and 37 in the right hemisphere are involved in both motor imagery and handedness recognition (Parsons \& Fox, 1998). Some of these areas are also associated with the mirror neuron system, and this finding suggests the participation of mirror neurons in handedness recognition, which was proposed by Parsons (1994) and Gawryszewski et al. (2007). The haptic identification of body parts activates specific areas on the occipitotemporal complex, the Haptic Face Area and the Haptic Body Area for face and non-face body parts, respectively (Kitada et al., 2009). These areas partially overlap with those activated by the visual identification of human faces (Fusiform Face Area) and other (Extrastriate Body Area) body parts (Peelen \& Downing, 2007).

Compared with vision, haptic object recognition is considerably slower, mostly because of the time necessary to extract localized information and integrate them into a coherent perception. The longer it takes to reach the perceptual threshold that allows a reasonable inference about the object's identity, the more demand is placed on the integration of spatial and temporal aspects of the stimulus, working memory, and attention (Loomis, Klatzky, \& Lederman, 1991; Lederman \& Klatzky, 2004; James et al., 2005; Scocchia, Stucchi, \& Loomis., 2009). The two-dimensional nature of the stimuli we used forced the subjects to use a rather stereotyped pattern of exploratory finger movements (i.e., the contour-following strategy), which is usually used when the form is the principal feature of the object and is characterized by a dynamic and time-consuming exploratory procedure in which the hand maintains contact with the object's contours (Lederman \& Klatzky, 1987). As expected, the response times we measured were relatively longer than the ones measured in visually based handedness recognition tasks (Parsons, 1994).

Humans recognize common nonbiological objects very effectively using haptic and visual recognition (Klatzky, Lederman, \& Metzger, 1985). Recent studies have shown that human body parts, such as faces (Kilgour
\& Lederman, 2002, 2006), hands, and feet (Kitada et al., 2009, 2010), and the facial expression of emotion (Lederman et al., 2007) can also be identified haptically.

Despite the differences in the dynamics of haptic and visual object exploration, our results indicate that both processes rely on similar motor imagery mechanisms for handedness identification. More specifically, the identical profile of response time variation as a function of stimulus orientation suggests that the same biomechanical constraints are enforced for both haptically and visually elicited motor imagery. Sensorimotor representations can be thought of as generic entities that can be recalled to help recognize the handedness of body parts, independent of the sensory modality used to categorize them and understand other motor actions.

\section{Acknowledgements}

We wish to thank CAPES, CNPq, FAPERJ, PIBICUFF/CNPq, and PROPP - UFF for financial support and Prof. Dr. Claudia D. Vargas (IBCCF-UFRJ) and Professor John Findlay (University of Durham, UK) for their wise and very helpful criticisms and suggestions on the manuscript.

\section{References}

Dellantonio, A., \& Spagnolo, F. (1990). Mental rotation of tactual stimuli. Acta Psychologica, 73, 245-257.

Gawryszewski, L.G., Silva-dos-Santos, C.F., Santos-Silva, J.C., Lameira, A.P., \& Pereira, A., Jr. (2007). Mental rotation of anthropoid hands: a chronometric study. Brazilian Journal of Medical and Biological Research, 40, 377-381.

Hunt, L.J., Janssen, M., Dagostino, J., \& Gruber, B. (1989). Haptic identification of rotated letters using the left or right hand. Perceptual and Motor Skills, 68, 899-906.

James, T.W., James, K.H., Humphrey, G.K., \& Goodale, M.A. (2005). Do visual and tactile object representations share the same neural substrate? In M.A. Heller, \& S. Ballesteros (Eds.), Touch and Blindness: Psychology and Neuroscience (pp. 139-157). Mahwah, NJ: Lawrence Erlbaum.

Jeannerod, M. (2001). Neural simulation of action: a unifying mechanism for motor cognition. Neuroimage, 14, S103-S109.

Kilgour, A., \& Lederman, S.J. (2002). Face recognition by hand. Perception and Psychophysics, 64, 339-352.

Kilgour, A.R., \& Lederman, S.J. (2006). A haptic face-inversion effect. Perception, 35, 921-931.

Kitada, R., Johnsrude, I.S., Kochiyama, T., \& Lederman, S.J. (2009). Functional specialization and convergence in the occipito-temporal cortex supporting haptic and visual identification of human faces and body parts: an fMRI study. Journal of Cognitive Neuroscience , 21, 2027-2045.

Kitada, R., Dijkerman, H.C., Soo, G., \& Lederman, S.J. (2010). Representing human hands haptically or visually from first-person versus third-person perspectives. Perception, 39, 236-254.

Klatzky R.L., Lederman S .J., \& Metzger, V.A. (1985). Identifying objects by touch: an "expert system." Perception and Psychophysics, 37, 299-302.

Lakatos, S., \& Marks, L.E. (1999). Haptic form perception: relative salience of local and global features. Perception and Psychophysics, $61,895-908$

Lameira, A.P., Guimarães Silva, S., Werneck-Galvão, C., Pereira, A. Jr., \& Gawryszewski, L.G. (2008a). Recognition of hand shape drawings on vertical and horizontal display. Psychology and Neuroscience, 1, 35-40.

Lameira, A.P., Guimarães Silva, S., Ferreira, F.M., Lima, L.V., Pereira, A., Jr., \& Gawryszewski, L.G. (2008b). Hand posture and 
motor imagery: a body part recognition study. Brazilian Journal of Physical Therapy, 12, 379-385.

Lederman, S.J., \& Klatzky, R.L. (1987). Hand movements: a window into haptic object recognition. Cognitive Psychology, 19, 342-368.

Lederman, S.J., \& Klatzky, R.L. (2004). Haptic identification of common objects: effects of constraining the manual exploration process. Perception and Psychophysics, 66, 618-628.

Lederman, S.J., Klatzky, R.L., Abramowicz, A., Salsman, K., Kitada, R., \& Hamilton, C. (2007). Haptic recognition of static and dynamic expressions of emotion in the live face. Psychological Science, 18, 158-164.

Loomis, J.M., Klatzky, R.L., \& Lederman, S.J. (1991). Similarity of tactual and visual picture recognition with limited field of view. Perception, 20, 167-177.

Marmor, G.S., \& Zaback, L.A. (1976) Mental rotation by the blind: does mental rotation depend on visual imagery? Journal of Experimental Psychology: Human Perception and Performance, 2, 515-521.

Norman, J.F., Norman, H.F., Clayton, A.M., Lianekhammy, J., \& Zielke, G. (2004). The visual and haptic perception of natural object shape. Perception and Psychophysics, 66, 342-351.

Oldfield, R.C. (1971). The assessment and analysis of handedness: the Edinburgh inventory. Neuropsychologia, 9, 97-113.

Parsons, L.M. (1987). Imagined transformation of one's hands and feet. Cognitive Psychology, 19, 178-241.
Parsons, L.M. (1994). Temporal and kinematic properties of motor behavior reflected in mentally simulated action. Journal of Experimental Psychology: Human Perception and Performance, 20, 709-730.

Parsons, L.M., \& Fox, P.T. (1998). The neural basis of implicit movements used in recognizing hand shape. Cognitive Neuropsychology, 15, 583-615.

Peelen, M.V., \& Downing, P.E. (2007). The neural basis of visual body perception. Nature Reviews Neuroscience, 8, 636-648.

Petit, L.S., Pegna, A.J., Mayer, E., \& Hauert, C.A. (2003). Representation of anatomical constraints in motor imagery: mental rotation of a body segment. Brain and Cognition, 51, 95-101.

Prather, S.C., \& Sathian, K. (2002). Mental rotation of tactile stimuli. Cognitive Brain Research, 14, 91-98.

Rösler, F., Röder, B., Heil, M., \& Hennighausen, E. (1993). Topographic differences of slow event-related brain potentials in blind and sighted adult human subjects during haptic mental rotation. Cognitive Brain Research, 1, 145-159.

Scocchia, L., Stucchi, N., \& Loomis, J.M. (2009). The influence of facing direction on the haptic identification of two dimensional raised pictures. Perception, 38, 606-612.

Shepard, R.N., \& Metzler, J. (1971). Mental rotation of threedimensional objects. Science, 171, 701-703. 